\title{
Bibliometric and Visualized Analyses of Research Studies on Different Analgesics in the Treatment of Orthopedic Postoperative Pain
}

\author{
Yunzhong Cheng $\mathbb{D}^{1,2}$ Honghao Yang $\mathbb{D}^{1},{ }^{1}$ Li Guan ${ }^{\mathbb{D}},{ }^{1}$ Yong Hai ${ }^{(D)},{ }^{1}$ and Aixing Pan $\mathbb{D}^{1}$ \\ ${ }^{1}$ Department of Orthopedic Surgery, Beijing Chao-Yang Hospital, Capital Medical University, Beijing 100020, China \\ ${ }^{2}$ Department of Neurobiology, School of Basic Medical Sciences, Beijing Key Laboratory of Neural Regeneration and Repair, \\ Beijing Institute for Brain Disorders, Capital Medical University, Beijing 100020, China
}

Correspondence should be addressed to Li Guan; guanlicy@sina.com and Yong Hai; yong.hai@ccmu.edu.cn

Received 21 December 2021; Accepted 28 January 2022; Published 24 February 2022

Academic Editor: Sidong Yang

Copyright (c) 2022 Yunzhong Cheng et al. This is an open access article distributed under the Creative Commons Attribution License, which permits unrestricted use, distribution, and reproduction in any medium, provided the original work is properly cited.

\begin{abstract}
Background. Pain following orthopedic surgery has always been a critical issue, which caused great distress to the patients. Analgesics in the treatment of postoperative pain following orthopedic surgery have aroused great attention from scholars, and numerous studies have been published in recent years. Bibliometrics could assist scholars in understanding the scope of research topics better, identifying research focuses and key literature, and analyzing the development and trend of analgesics in the treatment of postoperative pain following orthopedic surgery. Methods. Literature data were retrieved from the Science Citation Index Expanded (SCI-E) of Web of Science (WOS) Core collection database. The articles from 1992 to December 2021 on analgesics in the treatment of postoperative pain following orthopedic surgery were recruited. The citation reports including the publication numbers, h-index, total citations, and average citations in terms of authors, organizations, and countries were obtained. Top 20 research directions, funds, and journals with the most publications were charted. The co-authorship relations in the analysis units of authors, organizations, and countries were analyzed by the online bibliometric tool and VOSviewer software. The author's keywords co-occurrence overlay map was visualized by the VOSviewer software. Results. A total of 406 articles were retrieved from 1992 to December 4th, 2021, with 11,655 times cited, average citations of 28.57 per item, and an h-index of 55. The most high-yield publication year, authors, organizations, countries, research directions, funds, and journals were $2020(n=887)$, Ilfeld BM from University of California San Diego $(n=7)$, University of California System $(n=21)$, the USA $(n=178)$, Anesthesiology $(n=161)$, National Institutes of Health (NIH), USA, and United States Department of Health Human Services $(n=12)$, and Anesthesia and Analgesia $(n=29)$, respectively. Similarly, co-authoring analysis of publications regarding on different analgesics showed that the authors and countries with the most co-authorship strength were Carr Daniel B (total link strength $=6$ ) and the USA (total link strength $=30$ ), respectively. The highest occurrence keywords were "postoperative pain" with 135 occurrences (total link strength =784). The future research hotspots might be "acute pain," "outcomes," "oxycodone," "total hip," "replacement," and "United States." Conclusion. Analgesics in the treatment of postoperative pain following orthopedic surgery can be observed in this study by employing the online bibliometric tool and VOSviewer software, which established the relationship between the units of analysis. It can provide a meaningful resource with detailed information for orthopedic surgeons who would like to understand the trend in this field better. They can also benefit from the emphasis on citation count to carry out high-level research in the future.
\end{abstract}

\section{Introduction}

Postoperative pain has always been a problem plaguing clinical treatment. In addition to the pain of the incision, many other factors can also cause pain, especially following the orthopedic operations, such as periosteal irritation, swelling of the affected limb, increased bone fascia tension, postoperative compression bandaging, and external fixation 
[1]. More importantly, pain after orthopedic surgery becomes more common and more severe. What is worse, pain can increase cortisol, blood sugar, tea phenolamine in the body, and tissue metabolism, which is not conducive to wound healing. Therefore, the management of postoperative analgesia following orthopedic surgery is very important [2].

There are more than 53 million records and 1.18 billion cited references in the Science Citation Index Expanded (SCI-E) of Web of Science (WOS) Core collection database, which is an important resource for scientific statistics and evaluation [3]. More frequent citations of the article play a more important role in the field [4]. A bibliometric analysis and visualization tool can effectively assess the thematic development of structural contents and help readers understand a field comprehensively [5].

However, no bibliometric research on different analgesics in the treatment of postoperative pain following orthopedic surgery has been performed. This study aims to outline the intellectual connections within the dynamic changing of scientific knowledge in orthopedic postoperative analgesia using the WOS Core Collection database and the VOSviewer software.

\section{Methods}

The literature data were retrieved through SCI-E of WOS Core Collection database, which is widely applied in bibliometric research using an advanced search strategy. The search query was " $((()(\mathrm{TS}=($ Orthopedic OR Orthopedic Procedure OR Orthopedic Surgery OR Orthopedic Surgical Procedure)) AND TS $=($ Postoperative OR Postoperative Periods $)$ AND $\mathrm{TS}=($ Pain OR Physical Suffering OR Ache $))$ AND TS $=($ Analgesics OR anodyne OR Analgesic Drugs OR Analgesic OR Analgesic Agents OR Antinociceptive Agents)) AND $\mathrm{LA}=($ English $)$ AND DT $=($ Article $) . "$ Timespan $=$ all years. All articles were evaluated by two independent reviewers in order to confirm their relevance. Full records of all articles were searched on December 4th, 2021.

The trends of publications and citations were charted annually. The distribution of the bibliographic records per year in different countries was also obtained. The top 20 most cited articles were recorded and analyzed by the following information: first author, article title, journals of publication, year of publication, total number of citations, and average citations. The records, h-index, total citations, and average citations in terms of authors, organizations, and countries were tabulated directly. The top 20 research directions, funds, and journals with the most publications were charted. The co-authorship relations in the analysis units of authors, organizations, and countries were mapped by the online bibliometric tool (https://bibliometric. $\mathrm{com} /$ ) and VOSviewer 1.6.11 software (Nees Jan van Eck and Ludo Waltman, 2019). The author's keywords co-occurrence overlay map was implemented by VOSviewer, setting the minimum occurrences of a keyword to 5 times.

\section{Results}

3.1. Publication Outlines. A total of 406 articles were retrieved in the SCI-E of WOS Core Collection database from 1992 to December 4th, 2021, with 11,655 times cited, average citations of 28.57 per item, and an h-index of 55. Figure 1 shows the annual publications and sum of times cited per year on analgesics in the treatment of postoperative pain following orthopedic surgery. The first article was published in 1992, and the year with the most publications $(n=29)$ was 2020. The citation started in 1992, and the year with the most times cited was $2020(n=887)$. The results showed a fluctuating increase year by year.

The USA had contributed 178 articles $(43.842 \%)$ at the top. Canada was the second contributing country with 25 articles (6.157\%), followed by England with 22 articles (5.419\%) and France and Germany both with 20 articles (4.926\%). China only ranked 9th with 13 articles $(3.186 \%)$. Only two countries contributed articles in 1992. However, more and more countries published articles yearly, and the number of involved countries increased to ten in 2021. The USA dominates in this field almost every year. The distribution of the bibliographic records each year of the top 10 countries on analgesics in the treatment of postoperative pain following orthopedic surgery is shown in Figure 2.

\subsection{Top 20 Most Cited Articles on Different Analgesics.} This search collected a total of 406 articles between 1992 and 2021 from WOS. The top 20 most cited articles are given in Table 1, including first author, article title, journals of publication, year of publication, total number of citations, and average citations. The total citations of the top 20 articles ranged from 101 to 1013 . The average citations of the top 20 articles ranged from 4.21 to 40.52 . The most cited article had 1013 citations and was published in 1997 by Collins et al. [6], followed by Chung et al. [7] with 271 citations in 1997 and Sinatra et al. [8] with 252 citations in 2005. The first two published articles were by Laitinen and Nuutinen [9] and Baker [10] in February 1992, and the most recent articles were published in December 2021 by De Biase et al. [11] and Rajput et al. [12].

\subsection{Contribution of Authors, Organizations, and Countries.} There were 1,961 authors, 745 organizations, and 46 countries contributing to this field. Table 2 provides the top 5 high-yield authors (Ilfeld Brian M, Lauretti Gabriela Rocha, Carr Daniel B, Liu Spencer S, and Capdevila Xavier [13-17]), organizations (University of California System, Pennsylvania Commonwealth System of Higher Education Pcshe, Universidade De São Paulo, University of Pennsylvania, and Cleveland Clinic Foundation), and countries (the USA, Canada, England, France, and Germany), with the corresponding records, h-index, total citations, and average citations.

3.4. Contribution of Research Directions, Funds, and Journals. There were 37 research directions, 154 funds, and 174 journals contributing to this topic. Figure 3 shows the top 20 high-yield research directions, the top is Anesthesiology with 161 publications, followed by Neurosciences Neurology with 65 publications and Orthopedics with 55 publications. In the top 20 high-yield funds, National Institutes of Health 


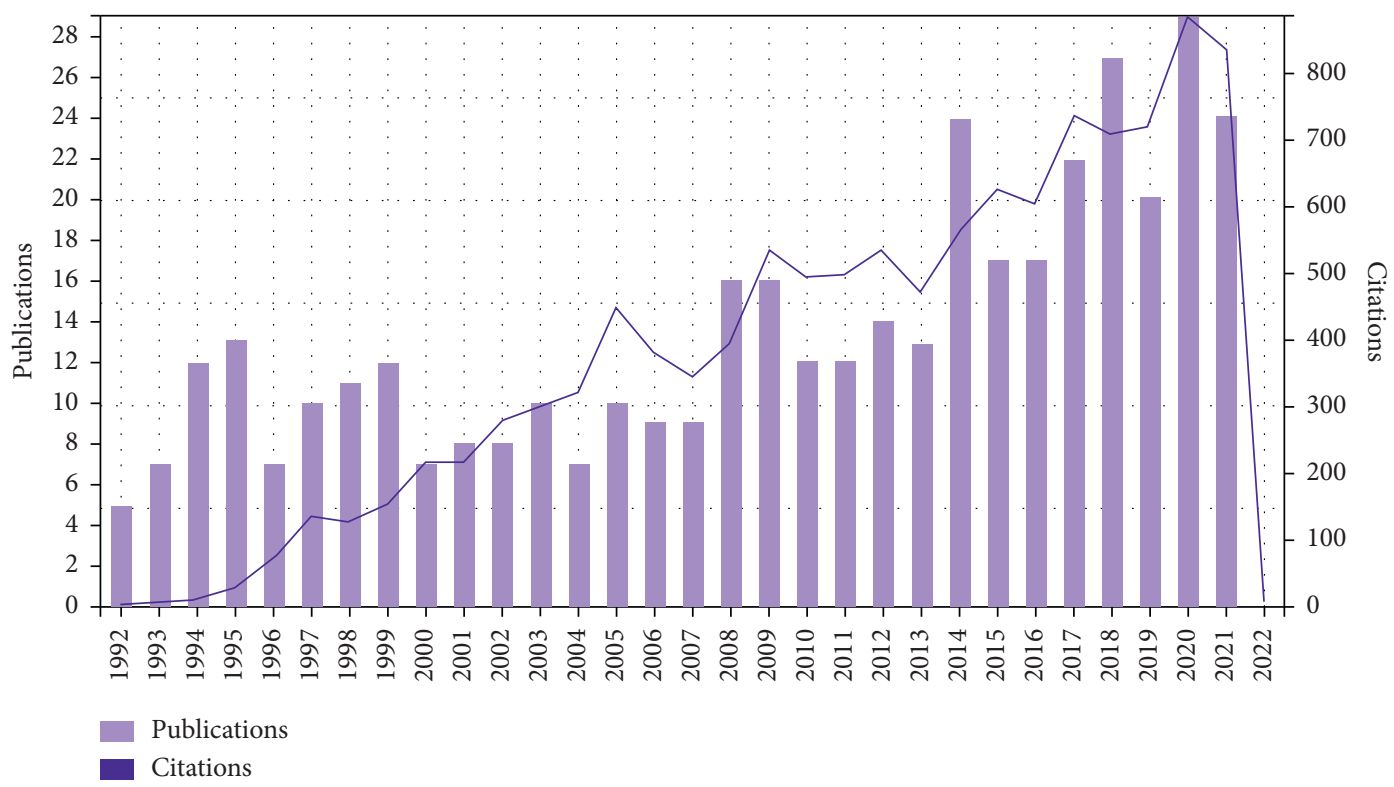

Figure 1: Annual publications (column chart) and sum of times cited per year (curve line) on analgesics in the treatment of orthopedic postoperative pain from 1992 to 2021.

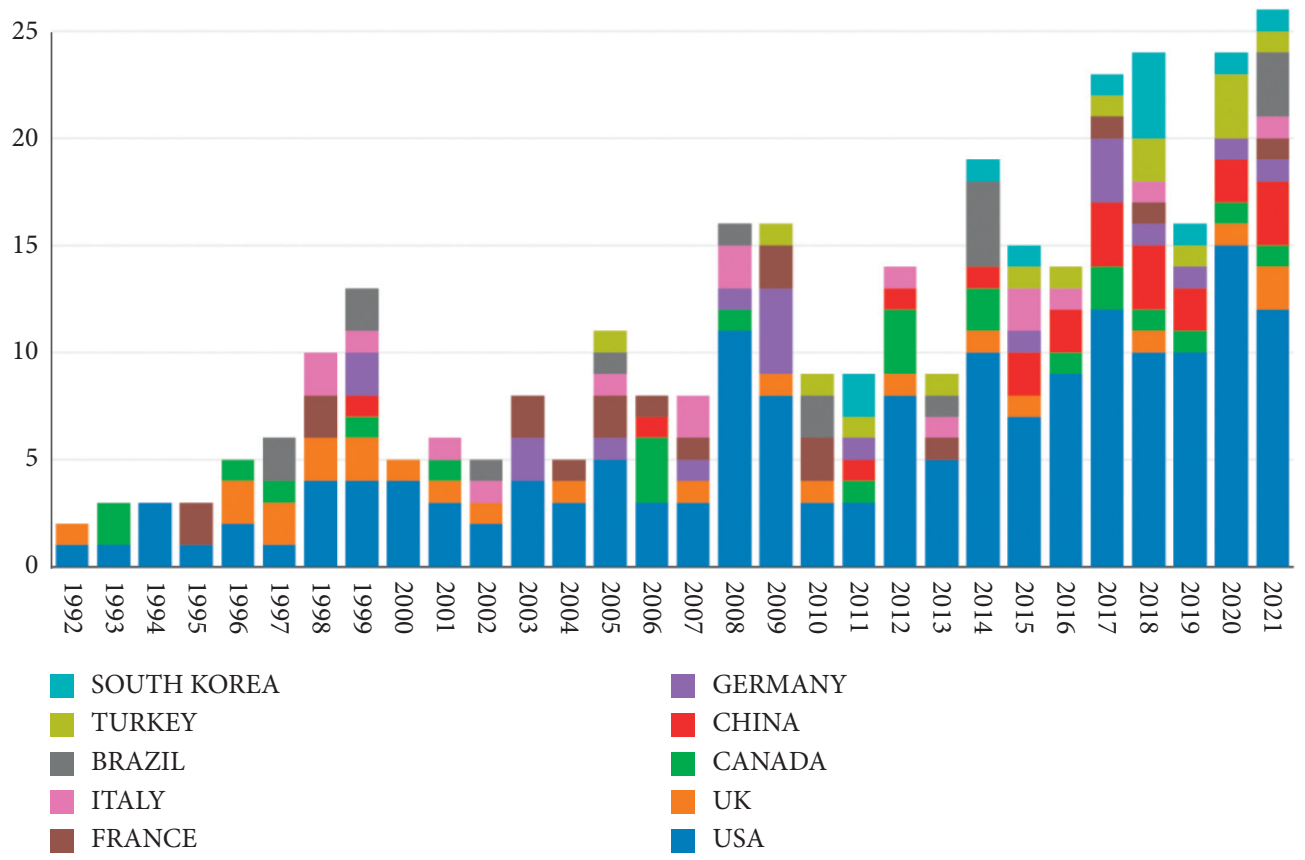

Figure 2: The distribution of the bibliographic records per year of the top 10 countries on analgesics in the treatment of orthopedic postoperative pain.

(NIH), USA, and United States Department of Health Human Services were tied for first place with 12 publications, followed by European Commission and NIH National Center for Advancing Translational Sciences (NCATS) both with 4 publications (Figure 4). Figure 5 shows the top 20 high-yield journals. Anesthesia and Analgesia had contributed 29 articles (7.108\%) at the top. Journal of Clinical Anesthesia was the second contributing journal with 19 articles (4.657\%), followed by Anesthesiology and British Journal of Anesthesia both with 12 articles (2.941\%).
3.5. Co-Authoring Analysis of Publications regarding Different analgesics. The authors with the most co-authorship strength were Carr Daniel B, Daniels et al. [18], Viscusi et al. [19], and Lauretti and Reis [20] (Table 3). The strongest collaborative country was the USA with 4,411 citations (total link strength $=30$ ), followed by France with 599 citations (total link strength =9), Canada with 997 citations (total link strength $=8$ ), Germany with 530 citations (total link strength $=8$ ), and Sweden with 279 citations (total link strength $=7$ ) (Figure 6). 
TABLE 1: Top 20 most cited articles on analgesics in the treatment of orthopedic postoperative pain.

\begin{tabular}{|c|c|c|c|c|c|}
\hline First author & Article title & Journal & $\begin{array}{c}\text { Publication } \\
\text { year }\end{array}$ & $\begin{array}{c}\text { Total } \\
\text { citations }\end{array}$ & $\begin{array}{l}\text { Average } \\
\text { citations }\end{array}$ \\
\hline Collins SL & $\begin{array}{l}\text { The visual analogue pain intensity scale: What is } \\
\text { moderate pain in millimetres? }\end{array}$ & Pain & 1997 & 1013 & 40.52 \\
\hline Chung F & $\begin{array}{l}\text { Postoperative pain in ambulatory surgery } \\
\text { Efficacy and safety of single and repeated }\end{array}$ & Anesthesia and Analgesia & 1997 & 271 & 10.84 \\
\hline Sinatra RS & $\begin{array}{l}\text { administration of } 1 \mathrm{~g} \text { intravenous acetaminophen } \\
\text { injection (paracetamol) for pain management } \\
\text { after major orthopedic surgery }\end{array}$ & Anesthesiology & 2005 & 252 & 14.82 \\
\hline Feldt KS & $\begin{array}{c}\text { Treatment of pain in cognitively impaired } \\
\text { compared with cognitively intact older patients } \\
\text { with hip-fracture }\end{array}$ & $\begin{array}{l}\text { Journal of the American } \\
\text { Geriatrics Society }\end{array}$ & 1998 & 192 & 8.00 \\
\hline Lascelles BDX & $\begin{array}{c}\text { Efficacy and kinetics of carprofen, administered } \\
\text { preoperatively or postoperatively, for the } \\
\text { prevention of pain in dogs undergoing } \\
\text { ovariohysterectomy }\end{array}$ & Veterinary Surgery & 1998 & 173 & 7.21 \\
\hline Reuben SS & $\begin{array}{l}\text { Postoperative analgesic effects of celecoxib or } \\
\text { rofecoxib after spinal fusion surgery }\end{array}$ & Anesthesia and Analgesia & 2000 & 169 & 7.68 \\
\hline Briggs $M$ & $\begin{array}{l}\text { A descriptive study of the use of visual analogue } \\
\text { scales and verbal rating scales for the assessment of } \\
\text { postoperative pain in orthopedic patients }\end{array}$ & $\begin{array}{l}\text { Journal of Pain and Symptom } \\
\text { Management }\end{array}$ & 1999 & 168 & 7.3 \\
\hline Rapp SE & $\begin{array}{c}\text { Acute pain management in patients with prior } \\
\text { opioid consumption: a case-controlled } \\
\text { retrospective review }\end{array}$ & Pain & 1995 & 161 & 5.96 \\
\hline Moore A & $\begin{array}{c}\text { Deriving dichotomous outcome measures from } \\
\text { continuous data in randomised controlled trials of } \\
\text { analgesics }\end{array}$ & Pain & 1996 & 158 & 6.08 \\
\hline Hebl JR & $\begin{array}{l}\text { A preemptive multimodal pathway featuring } \\
\text { peripheral nerve block improves perioperative } \\
\text { outcomes after major orthopedic surgery }\end{array}$ & $\begin{array}{l}\text { Regional Anesthesia and Pain } \\
\text { Medicine }\end{array}$ & 2008 & 153 & 10.93 \\
\hline White PF & $\begin{array}{l}\text { The use of a continuous popliteal sciatic nerve } \\
\text { block after surgery involving the foot and ankle: } \\
\text { Does it improve the quality of recovery? }\end{array}$ & Anesthesia and Analgesia & 2003 & 134 & 7.05 \\
\hline Liu SS & $\begin{array}{l}\text { Patient-controlled epidural analgesia with } \\
\text { bupivacaine and fentanyl on hospital wards: } \\
\text { prospective experience with 1,030 surgical patients }\end{array}$ & Anesthesiology & 1998 & 129 & 5.38 \\
\hline Gwirtz KH & $\begin{array}{c}\text { The safety and efficacy of intrathecal opioid } \\
\text { analgesia for acute postoperative pain: Seven years' } \\
\text { experience with } 5969 \text { surgical patients at Indiana } \\
\text { University Hospital }\end{array}$ & Anesthesia and Analgesia & 1999 & 125 & 5.43 \\
\hline Dohoo SE & $\begin{array}{l}\text { Postoperative use of analgesics in dogs and cats by } \\
\text { Canadian veterinarians }\end{array}$ & $\begin{array}{c}\text { Canadian Veterinary Journal- } \\
\text { Revue Veterinaire } \\
\text { Canadienne }\end{array}$ & 1996 & 125 & 4.81 \\
\hline Gimbel JS & $\begin{array}{l}\text { Efficacy and tolerability of celecoxib versus } \\
\text { hydrocodone/acetaminophen in the treatment of } \\
\text { pain after ambulatory orthopedic surgery in adults }\end{array}$ & Clinical Therapeutics & 2001 & 114 & 5.43 \\
\hline $\begin{array}{l}\text { Hernandez- } \\
\text { Palazon J }\end{array}$ & $\begin{array}{l}\text { Intravenous administration of propacetamol } \\
\text { reduces morphine consumption after spinal fusion } \\
\text { surgery }\end{array}$ & Anesthesia and Analgesia & 2001 & 109 & 5.19 \\
\hline Collins SL & $\begin{array}{l}\text { Seeking a simple measure of analgesia for mega- } \\
\text { trials: Is a single global assessment good enough? }\end{array}$ & Pain & 2001 & 108 & 5.14 \\
\hline Marino J & $\begin{array}{c}\text { Continuous lumbar plexus block for postoperative } \\
\text { pain control after total hip arthroplasty a } \\
\text { randomized controlled trial }\end{array}$ & $\begin{array}{l}\text { Journal of Bone and Joint } \\
\text { Surgery-American Volume }\end{array}$ & 2009 & 105 & 8.08 \\
\hline Grisneaux E & $\begin{array}{l}\text { Comparison of ketoprofen and carprofen } \\
\text { administered prior to orthopedic surgery for } \\
\text { control of postoperative pain in dogs }\end{array}$ & $\begin{array}{l}\text { Journal of the American } \\
\text { Veterinary Medical } \\
\text { Association }\end{array}$ & 1999 & 101 & 4.39 \\
\hline Peduto VA & $\begin{array}{c}\text { Efficacy of propacetamol in the treatment of } \\
\text { postoperative pain: morphine-sparing effect in } \\
\text { orthopedic surgery }\end{array}$ & $\begin{array}{l}\text { Acta Anaesthesiologica } \\
\text { Scandinavica }\end{array}$ & 1998 & 101 & 4.21 \\
\hline
\end{tabular}


TABLE 2: The top five high-yield countries, organizations, and authors on analgesics in the treatment of orthopedic postoperative pain from 1985 to 2021 .

\begin{tabular}{|c|c|c|c|c|c|c|}
\hline Category & Rank & Items & Records & $\begin{array}{l}\text { H- } \\
\text { index }\end{array}$ & $\begin{array}{c}\text { Total } \\
\text { citations }\end{array}$ & Average citations \\
\hline \multirow{5}{*}{ Author } & 1 & Ilfeld BM, University of California San Diego & 7 & 5 & 226 & 32.29 \\
\hline & 2 & Lauretti GR, University of São Paulo & 6 & 4 & 171 & 28.5 \\
\hline & 3 & Carr DB, Tufts University & 5 & 5 & 77 & 15.4 \\
\hline & 3 & Liu SS, Virginia Mason Medical Center & 5 & 5 & 220 & 44 \\
\hline & 4 & $\begin{array}{c}\text { Capdevila X, CHU de Montpellier Anesthesiol and Crit Care } \\
\text { Dept }\end{array}$ & 4 & 4 & 197 & 49.25 \\
\hline \multirow{5}{*}{ Organization } & 1 & University of California System & 21 & 12 & 602 & 28.67 \\
\hline & 2 & $\begin{array}{l}\text { Pennsylvania Commonwealth System of Higher Education } \\
\text { Pcshe }\end{array}$ & 9 & 5 & 160 & 17.78 \\
\hline & 2 & Universidade De Sao Paulo & 9 & 5 & 206 & 22.89 \\
\hline & 3 & University of Pennsylvania & 8 & 6 & 124 & 15.5 \\
\hline & 4 & Cleveland Clinic Foundation & 7 & 3 & 120 & 17.14 \\
\hline \multirow{5}{*}{ Country } & 1 & USA & 178 & 36 & 4777 & 26.84 \\
\hline & 2 & Canada & 25 & 18 & 1272 & 50.88 \\
\hline & 3 & England & 22 & 16 & 2064 & 93.82 \\
\hline & 4 & France & 20 & 13 & 667 & 33.35 \\
\hline & 4 & Germany & 20 & 13 & 531 & 26.55 \\
\hline
\end{tabular}

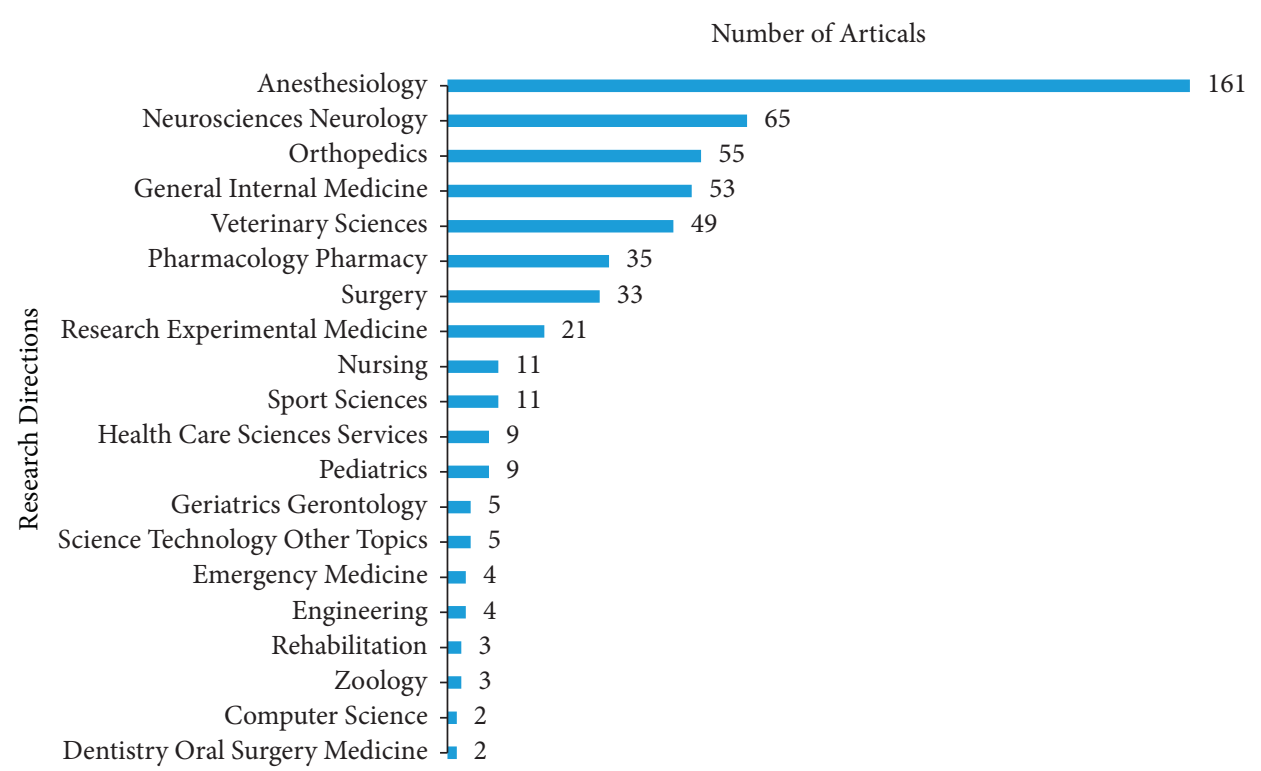

FIGURE 3: Top 20 research directions with the most publications on analgesics in the treatment of orthopedic postoperative pain.

3.6. Keywords Co-Occurrence. The overlay visualization of the top 162 co-occurrence keywords is shown in Figure 7. The highest occurrence keyword was "postoperative pain" with 135 occurrences (total link strength $=784$ ), followed by "morphine" with 91 occurrences (total link strength $=616$ ), "orthopedic-surgery" with 91 occurrences (total link strength $=582$ ), "analgesia" with 85 occurrences (total link strength $=550$ ), and "pain" with 83 occurrences (total link strength $=522$ ). The most recent keywords were "acute pain," "outcomes," "oxycodone," "total hip," "replacement," and "United States."

\section{Discussion}

Bibliometrics mainly collects bibliographic databases and bibliometric features and uses mathematical and statistical methods to qualitatively and quantitatively analyze the relevant information of the literature, such as the distribution of countries, authors, journals, institutions, and funds. It also helps researchers grasp the development trend of this field intuitively and quickly [21, 22]. Using visual analysis software to analyze the literature further, researchers can find current research hotspots 


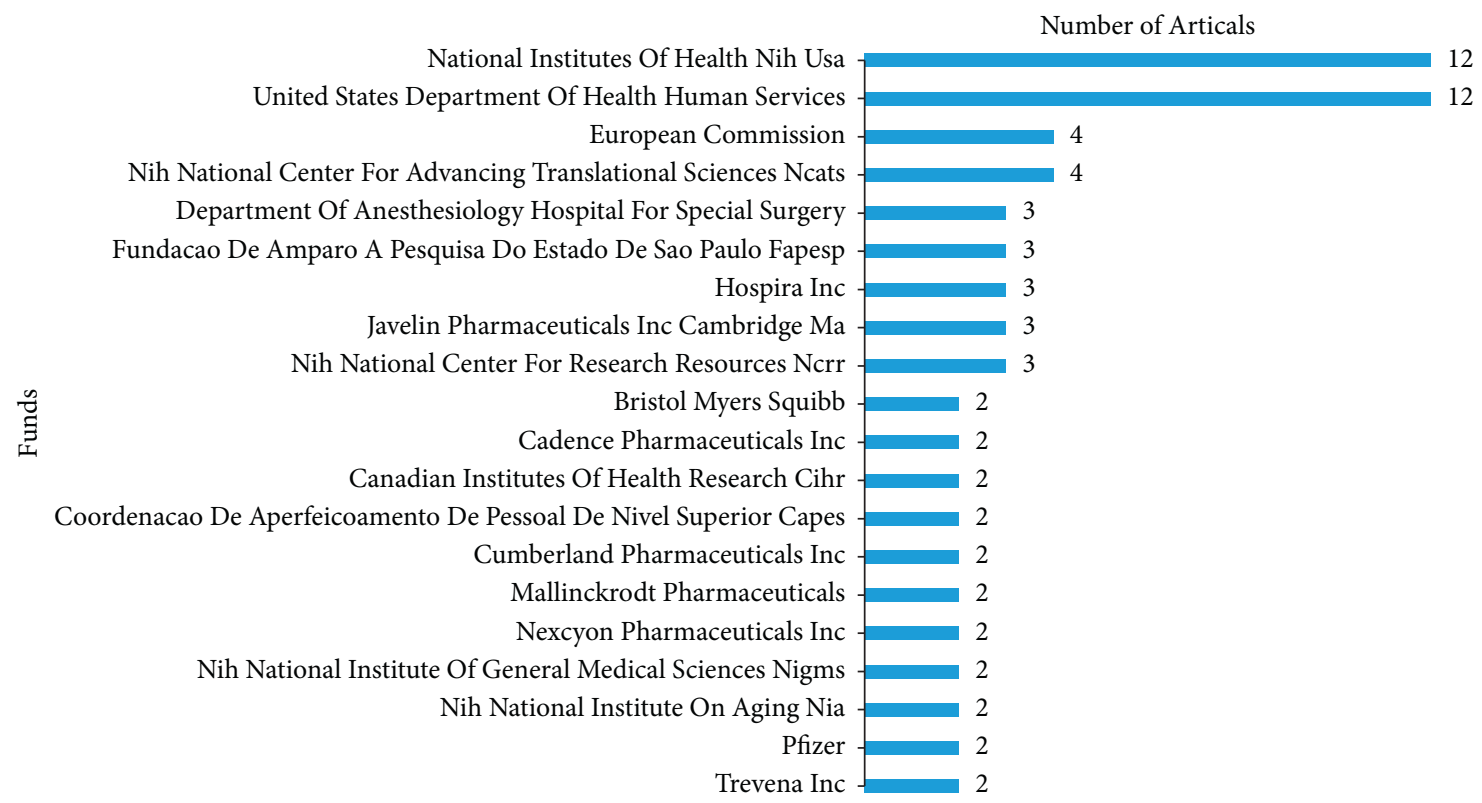

FIgURE 4: Top 20 funds for the most publications on analgesics in the treatment of orthopedic postoperative pain.

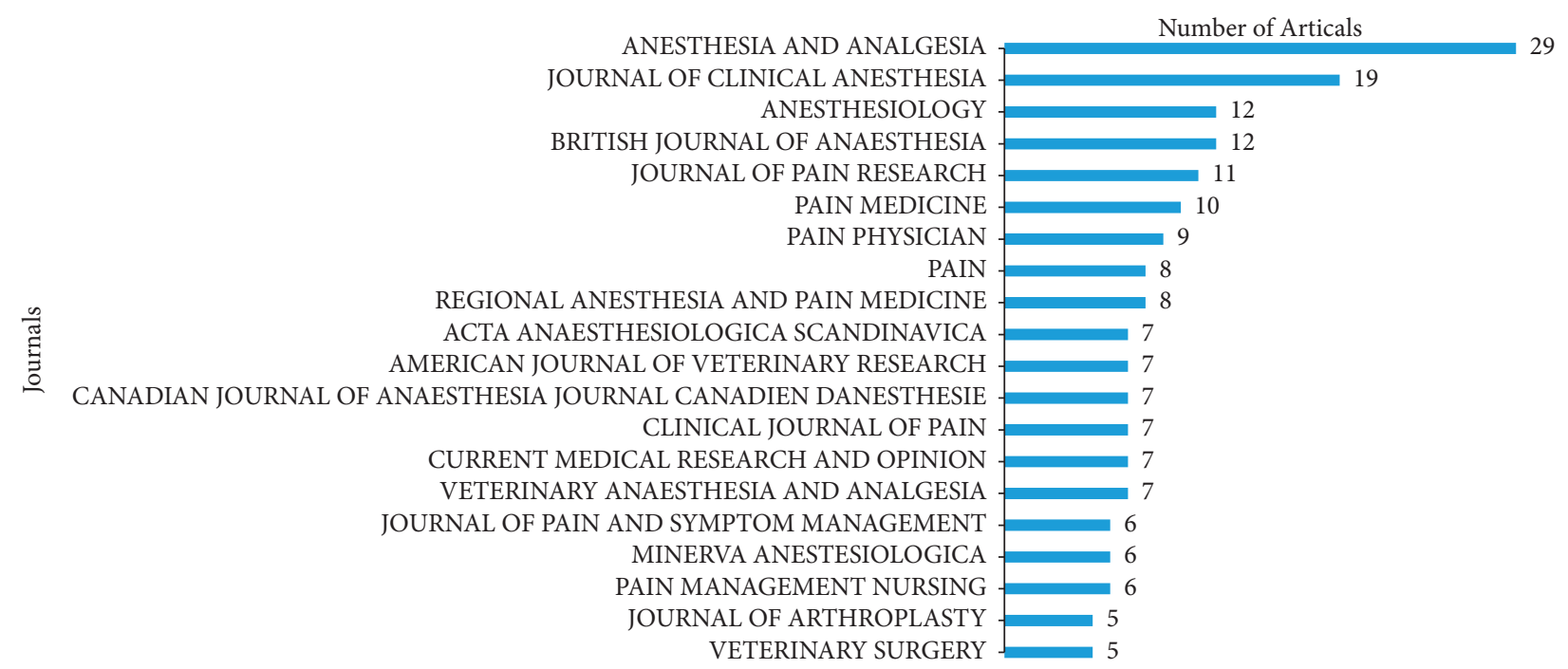

FIGURE 5: Top 20 journals with the most publications on analgesics in the treatment of orthopedic postoperative pain.

TABLE 3: Co-author analysis of publications regarding analgesics in the treatment of orthopedic postoperative pain.

\begin{tabular}{lccc}
\hline Author & Number of articles & Citations & Total link strength \\
\hline Carr DB & 5 & 77 & 6 \\
Daniels SE & 4 & 124 & 6 \\
Singla N & 4 & 83 & 6 \\
Lauretti GR & 5 & 171 & 4 \\
Reis MP & 4 & 167 & 4 \\
Turan A & 4 & 60 & 3 \\
Ilfeld BM & 4 & 82 & 2 \\
Minkowitz HS & 4 & 169 & 1 \\
\hline
\end{tabular}




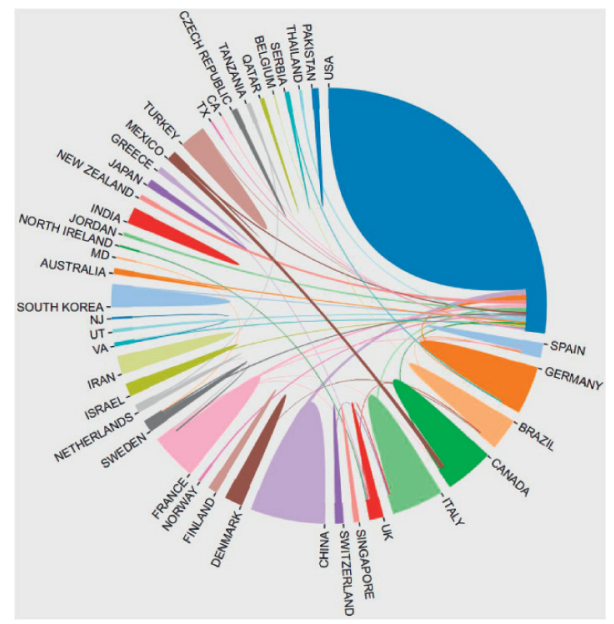

FIGURE 6: Country co-authoring analysis of publications regarding analgesics in the treatment of orthopedic postoperative pain.

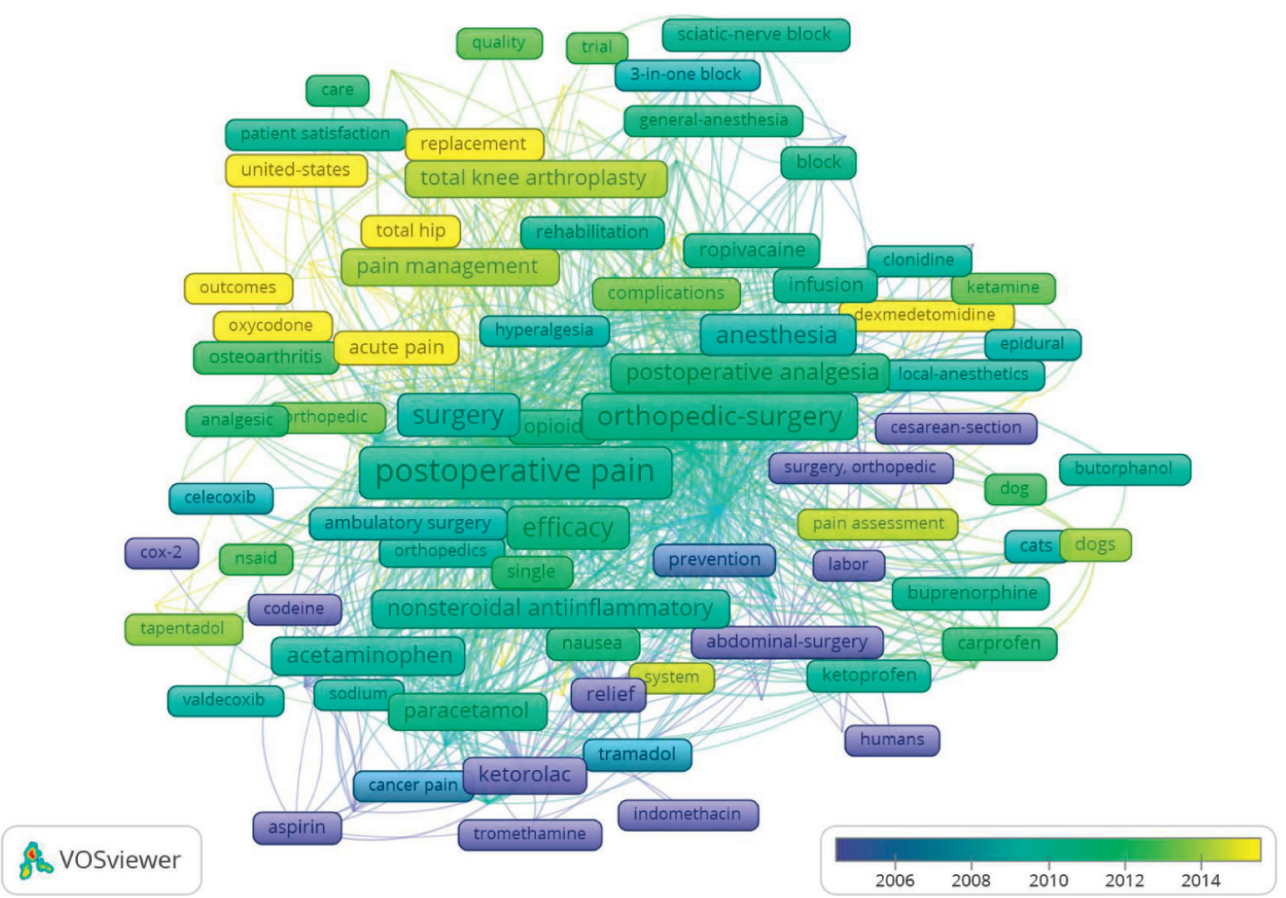

FIGURE 7: Keywords co-occurrence overlay mapping on analgesics in the treatment of orthopedic postoperative pain. Each frame indicates a keyword. The rainbow color marks the average publication year from violet (further year) to yellow (recent year) in the range of spectrum. The larger scale of a keyword is according to the higher frequency, while the closer distance between the two keywords represents the stronger co-occurrence.

and directions in this field. These methodologies have been widely applied in orthopedic research studies $[23,24]$.

4.1. Analysis on Publication Outlines. The popularity of a specific topic can be reflected by the number of publications. The study on analgesics in the treatment of postoperative pain following orthopedic surgery was initially published in 1992. The number of articles published fluctuated around ten from 1992 to 2007 and increased significantly from 2008 to 2021. Meanwhile, the quality of a specific topic can be judged by the number of citations [25]. There was an exponential growth in the citation times from 1992 to 2021. From Figure 1, we can learn that the future trend on analgesics in treating orthopedic postoperative pain looks promising.

As shown in Figure 2, the number of articles published from the USA is dominant in this field, followed by the UK and Canada. The article initially published from China was in 1999. The number of articles published from China is far less than that in the USA, which may be due to less attention paid to this field by Chinese scholars. 
4.2. Analysis on Top 20 Most Cited Articles on Different Analgesics. Citation analysis is a systematic method to evaluate the influence of scientific research [26]. An article with more frequent citation can be recognized as more influential in the specific field [4]. As given in Table 1, the total citation of each article on different analgesics was more than 100. The most cited article was a clinical trial by Collins et al. in 1997 in Pain [6], focusing on visual analogue scales (VAS). The results indicate that if a patient records a VAS score over $30 \mathrm{~mm}$ at baseline, they would probably have recorded at least moderate pain on a 4-point categorical scale. After that, the VAS score has been more widely used by many scholars, which may explain why this article was ranked at the top with 1013 citations.

The second most cited article was a retrospective review by Chung et al. in 1997 in Anesthesia and Analgesia [7], focusing on the pattern of pain in ambulatory surgical patients and determining those factors that predict postoperative pain. The final results of the article showed that anesthesiologists give adequate analgesia by taking into consideration the body mass index of the patient, the duration of anesthesia, and the type of surgery. Better methods of postoperative pain treatment, such as using NSAIDs, regional techniques, and multimodal analgesia techniques, are needed. The third most cited article was a clinical trial by Sinatra et al. in 2005 in Anesthesiology [8], focusing on pain intensity, pain relief, and morphine use. The results indicate that intravenous acetaminophen, $1 \mathrm{~g}$, administration over a 24-h period in patients with moderate to severe pain after orthopedic surgery could be well tolerated with rapid and effective analgesia.

The latest literature was a randomized controlled trial by Marino et al. in 2009 in Journal of Bone and Joint Surgery, paying attention to continuous lumbar plexus block for postoperative pain control after total hip arthroplasty. The conclusion was that continuous lumbar plexus and femoral blocks significantly reduce the need for opioids and decrease related side effects [27]. Another literature was a retrospective research by Hebl JR in 2008 in Regional Anesthesia and Pain Medicine, suggesting that a preemptive multimodal pathway featuring peripheral nerve block improves perioperative outcomes after major orthopedic surgery [28].

4.3. Analysis on Contribution of Authors, Organizations, and Countries. H-index refers to $h$ articles in the literature that have been cited at least $h$ times by other scholars, which is a measure to evaluate an author or country by the number of academic output and the index of the academic output level $[29,30]$. The total number of references cited refers to the number of times a document has been cited in a certain period, an important indicator for evaluating individual national influence [31].

Among the top five high-yield authors, three come from the USA, Ilfeld BM from University of California San Diego, Carr DB from Tufts University, and Liu SS from Virginia Mason Medical Center. Similarly, four were in the USA among the top five high-yield organizations, including University of California System,
Pennsylvania Commonwealth System of Higher Education Pcshe, University of Pennsylvania, and Cleveland Clinic Foundation. This may explain why the USA was ranked at the top one with a total of 178 records, which is far more than that in other countries (Table 2).

\subsection{Analysis on Contribution of Research Directions, Funds,} and Journals. As shown in Figures 3-5, anesthesiology, neurosciences, neurology, and orthopedics were the hot research directions, which will help orthopedic physicians to catch the right directions better.

In addition, National Institutes of Health (NIH), USA, and United States Department of Health Human Services were the most high-yield funds. Both of them belong to the USA. This was a good reason to explain why the USA was dominant in this field.

Identifying the dominant journals in a specific topic can help scholars construct scientific achievement. Anesthesia and Analgesia, Journal of Clinical Anesthesia, Anesthesiology, and British Journal of Anesthesia were the most high-yield journals. Paying more attention to high-yield journals can assist scholars in accessing the most authoritative knowledge framework and the orientation of manuscript submitting. The publishers of these journals belong to the USA, while the rest one is from the UK. Researchers may benefit from this important information and realize the deficiencies when high-level articles appear [32].

4.5. Analysis on Co-Authoring Analysis of Publications regarding Different Analgesics. VOSviewer was used for cooperation network analysis of authors, organizations, and countries [33]. Carr DB, Daniels SE, and Singla N were the authors with the most link strength. However, the most link strength was only six, which indicated that the cooperation between the authors was less (Table 3 ).

As shown in Figure 6, the strongest collaborative countries were the USA with 4,411 citations (total link strength $=30$ ), followed by France with 599 citations (total link strength $=9$ ) and Canada with 997 citations (total link strength $=8$ ). The rest were mainly from developed countries. The result showed that the USA have the most cooperation with other countries.

4.6. Analysis on Keywords Co-Occurrence. VOSviewer was also used to generate a keyword co-occurrence map [34]. The highest occurrence keyword was "postoperative pain" with 135 occurrences (total link strength $=784$ ), followed by "morphine" with 91 occurrences (total link strength $=616$ ) and "orthopedic-surgery" with 91 occurrences (total link strength $=582$ ). The most recent keyword was "acute pain," "outcomes," "oxycodone," "total hip," "replacement," and "United States," which indicated that these keywords might be the future research hotspots (Figure 7). 


\section{Limitations}

As all we know, bibliometric analysis has been widely used to measure the impact of articles in recent years. However, there are still some limitations to this method. First and foremost, we only used the core collection of WOS to search literature, which is a single database. The more databases we use, the more information we can get and analyze. Other databases such as InCites and MEDLINE should be considered in the future. Second, the main language of WOS is English. Articles written in other languages are excluded, which means some relevant articles be omitted. Third, the citation number of each study is time-dependent. For different time points to search the articles, different citations may be obtained. However, the trend of citation number of each study is nearly the same.

This study has several advantages despite the limitations mentioned. It is the first study using the bibliometric method to search and identify literature on analgesics in the treatment of postoperative pain following orthopedic surgery, which has attracted increasing attention in recent years. Most importantly, our study provides valuable information for orthopedic surgeons and researchers in this field.

\section{Conclusion}

To conclude, we researched and analyzed the literature information regarding authors, organizations, countries, research directions, funds, and journals and analyzed the thematic development and future research hotspots. Our research observes the raising concern on analgesics in the treatment of orthopedic postoperative pain in recent years. Anesthesia and Analgesia, Journal of Clinical Anesthesia, Anesthesiology, and British Journal of Anesthesia are the most influential journals. The future research hotspots might be "acute pain," "outcomes," "oxycodone," "total hip," "replacement," and "United States."

\section{Data Availability}

The data used to support the findings of this study are available from the corresponding author upon request.

\section{Disclosure}

Yunzhong Cheng and Honghao Yang are the co-first authors of this study.

\section{Conflicts of Interest}

The authors declare that they have no conflicts of interest.

\section{Authors' Contributions}

Yunzhong Cheng took part in data collection and wrote the article; Honghao Yang was responsible for data analysis and contributed all the figures; Aixing Pan reviewed and edited the article; and Li Guan and Yong Hai supervised the study. All authors have read and approved the content of the manuscript.

\section{References}

[1] H. Kehlet and J. B. Dahl, "Anaesthesia, surgery, and challenges in postoperative recovery," Lancet, vol. 362, no. 9399, pp. 1921-1928, 2003.

[2] M. H. Bourne, "Analgesics for orthopedic postoperative pain," American Journal of Orthopedics (Belle Mead, N.J.), vol. 33, no. 3, pp. 128-135, 2004.

[3] W. Xu, H.-K. Choi, and L. Huang, "State of panax ginseng research: a global analysis," Molecules, vol. 22, no. 9, p. 1518, 2017.

[4] A. Eyre-Walker and N. Stoletzki, "The assessment of science: the relative merits of post-publication review, the impact factor, and the number of citations," PLoS Biology, vol. 11, no. 10, Article ID e1001675, 2013.

[5] L. Wang, W. Feng, J. Duan, and J. Liang, "Pharmacovigilance bibliometrics: visualizing thematic development in the category of pharmacology and pharmacy in Web of science," Frontiers in Pharmacology, vol. 12, Article ID 731757, 202.

[6] S. L. Collins, R. A. Moore, and H. J. McQuay, "The visual analogue pain intensity scale: what is moderate pain in millimetres?" Pain, vol. 72, no. 1-2, pp. 95-97, 1997.

[7] F. Chung, E. Ritchie, and J. Su, "Postoperative pain in ambulatory surgery," Anesthesia and Analgesia, vol. 85, no. 4, pp. 808-816, 1997.

[8] R. S. Sinatra, J. S. Jahr, L. W. Reynolds, E. R. Viscusi, S. B. Groudine, and C. Payen-Champenois, "Efficacy and safety of single and repeated administration of 1 gram intravenous acetaminophen injection (paracetamol) for pain management after major orthopedic surgery," Anesthesiology, vol. 102, no. 4, pp. 822-831, 2005.

[9] J. Laitinen and L. Nuutinen, "Intravenous diclofenac coupled with PCA fentanyl for pain relief after total hip replacement," Anesthesiology, vol. 76, no. 2, pp. 194-198, 1992.

[10] A. B. Baker, "Analgesia for day surgery," Medical Journal of Australia, vol. 156, no. 4, pp. 274-280, 1992.

[11] G. De Biase, S. E. Gruenbaum, J. L. West et al., "Spinal versus general anesthesia for minimally invasive transforaminal lumbar interbody fusion: implications on operating room time, pain, and ambulation," Neurosurgical Focus, vol. 51, no. 6, p. E3, 2021.

[12] K. Rajput, C. B. Reid, D. Yanez, D Shiwlochan, S Ohanyan, and R Chow, "Patterns of use of opioid sparing adjuncts for perioperative pain management of patients on chronic opioids," Pain Physician, vol. 24, no. 8, pp. 577-586, 2021.

[13] B. M. Ilfeld, A. Plunkett, A. M. Vijjeswarapu et al., "Percutaneous peripheral nerve stimulation (neuromodulation) for postoperative pain: a randomized, sham-controlled pilot study," Anesthesiology, vol. 135, no. 1, pp. 95-110, 2021.

[14] G. R. Lauretti, F. S. Veloso, A. T. Kitayama, and A. L. Mattos, "Low-dose spinal neostigmine further enhances the analgesic effect of spinal bupivacaine combined with epidural dexamethasone, following orthopedic surgery," Journal of Research in Medical Sciences: The Official Journal of Isfahan University of Medical Sciences, vol. 19, no. 9, pp. 801-806, 2014.

[15] T. Gan, N. Singla, S. E. Daniels et al., "Postoperative opioid sparing with injectable hydroxypropyl- $\beta$-cyclodextrin-diclofenac: pooled analysis of data from two Phase III clinical trials," Journal of Pain Research, vol. 20, no. 10, pp. 15-29, 2016. 
[16] S. S. Liu, J. J. Bae, M. Bieltz, B. Wukovits, and Y. Ma, “A prospective survey of patient-controlled epidural analgesia with bupivacaine and clonidine after total hip replacement," Anesthesia \& Analgesia, vol. 113, no. 5, pp. 1213-1217, 2011.

[17] X. Capdevila, C. Dadure, S. Bringuier et al., "Effect of patientcontrolled perineural analgesia on rehabilitation and pain after ambulatory orthopedic surgery," Anesthesiology, vol. 105, no. 3, pp. 566-573, 2006.

[18] S. E. Daniels, T. J. Gan, D. A. Hamilton et al., "A pooled analysis evaluating renal safety in placebo- and active comparator-controlled phase III trials of multiple-dose injectable HP $\beta$ CD-diclofenac in subjects with acute postoperative pain," Pain Medicine, vol. 17, no. 12, pp. 2378-2388, 2016.

[19] E. R. Viscusi, F. Skobieranda, D. G. Soergel, E. Cook, D. A. Burt, and N. Singla, "APOLLO-1: a randomized placebo and active-controlled phase III study investigating oliceridine (TRV130), a G protein-biased ligand at the $\mu$-opioid receptor, for management of moderate-to-severe acute pain following bunionectomy," Journal of Pain Research, vol. 12, no. 12, pp. 927-943, 2019.

[20] G. Lauretti and M. Reis, "Postoperative analgesia and antiemetic efficacy after subarachnoid neostigmine in orthopedic surgery," Regional Anesthesia and Pain Medicine, vol. 22, no. 4, pp. 337-342, 1997.

[21] D. Xing, Y. Zhao, S. Dong, and J. Lin, "Global research trends in stem cells for osteoarthritis: a bibliometric and visualized study," International Journal of Rheumatic Diseases, vol. 21, no. 7, pp. 1372-1384, 2018.

[22] W.-J. Zhang, W. Ding, H. Jiang, Y.-F. Zhang, and J.-L. Zhang, "National representation in the plastic and reconstructive surgery literature," Annals of Plastic Surgery, vol. 70, no. 2, pp. 231-234, 2013.

[23] H. Wu, K. Cheng, Q. Guo et al., "Mapping knowledge structure and themes trends of osteoporosis in rheumatoid arthritis: a bibliometric analysis," Frontiers in Medicine, vol. 8, no. 8, Article ID 787228, 2021.

[24] K. Vishwanathan, S. B. S. Kambhampati, M. K. Patralekh, A. Vaish, and R. Vaishya, "Bibliometric analysis of the top 50 most cited publications of the Journal of Clinical Orthopaedics and Trauma," Journal of Clinical Orthopaedics and Trauma, vol. 22, no. 22, Article ID 101590, 2021.

[25] H. Lin, X. Wang, M. Huang et al., "Research hotspots and trends of bone defects based on Web of Science: a bibliometric analysis," Journal of Orthopaedic Surgery and Research, vol. 15, no. 1, p. 463, 2020.

[26] H. F. Moed, "New developments in the use of citation analysis in research evaluation," Archivum Immunologiae et Therapiae Experimentalis, vol. 57, no. 1, pp. 13-18, 2009.

[27] J. Marino, J. Russo, M. Kenny, R. Herenstein, E. Livote, and J. E. Chelly, "Continuous lumbar plexus block for postoperative pain control after total hip arthroplasty," Journal of Bone and Joint Surgery American Volume, vol. 91, no. 1, pp. 29-37, 2009.

[28] J. R. Hebl, J. A. Dilger, D. E. Byer et al., “A pre-emptive multimodal pathway featuring peripheral nerve block improves perioperative outcomes after major orthopedic surgery," Regional Anesthesia and Pain Medicine, vol. 33, no. 6, pp. 510-517, 2008.

[29] M. V. Root Kustritz and A. J. Nault, "Measuring productivity and impact of veterinary education-related research at the institutional and individual levels using the H-index," Journal of Veterinary Medical Education, vol. 47, no. 4, pp. 414-420, 2020 .
[30] M. T. Kalcioglu, Y. Ileri, O. I. Ozdamar, U. Yilmaz, and M. Tekin, "Evaluation of the academic productivity of the top 100 worldwide physicians in the field of otorhinolaryngology and head and neck surgery using the Google Scholar h-index as the bibliometrics ranking system," The Journal of Laryngology \& Otology, vol. 132, no. 12, pp. 1097-1101, 2018.

[31] Y. Le, S. Cao, M. Wang, X. Lin, and B. Qian, "A bibliometric and visualized analysis of nursing informatics competencies in China (2000-2020)," Studies in Health Technology and Informatics, vol. 15, no. 284, pp. 403-407, 2021.

[32] M. Yin, C. Xu, and W. Mo, "The 100 most cited articles on lumbar spinal stenosis: a bibliometric analysis," Global Spine Journal, vol. 1, no. 11, Article ID 2192568220952074, 2020.

[33] X. Mao, L. Guo, P. Fu, and C. Xiang, "The status and trends of coronavirus research,” Medicine (Baltimore), vol. 99, no. 22, Article ID e20137, 2020.

[34] A.-R. Kim and H. Y. Park, "Theme trends and knowledgerelationship in lifestyle research: a bibliometric analysis," International Journal of Environmental Research and Public Health, vol. 18, no. 14, p. 7503, 2021. 